\title{
Agreement between chest ultrasonography and chest X-ray in patients who have undergone thoracic surgery: preliminary results
}

Andrea Smargiassi ${ }^{1 *+}$, Riccardo Inchingolo ${ }^{1 \dagger}$, Marco Chiappetta ${ }^{2}$, Leonardo Petracca Ciavarella ${ }^{2}$, Stefania Lopatriello ${ }^{1}$, Giuseppe Maria Corbo ${ }^{1,3}$, Stefano Margaritora ${ }^{2,3}$ and Luca Richeldi ${ }^{1,3}$

\begin{abstract}
Background: Chest Ultrasonography (chest US) has shown good sensibility in detecting pneumothorax, pleural effusions and peripheral consolidations and it can be performed bedside.

Objectives: The aim of the study was to analyze agreement between chest US and chest X-ray in patients who have undergone thoracic surgery and discuss cases of discordance.

Methods: Patients undergoing thoracic surgery were retrospectively selected. Patients underwent routinely Chest $X$-ray (CXR) during the first $48 \mathrm{~h}$ after surgery. Chest US have been routinely performed in all selected patients in the same date of CXR. Chest US operators were blind to both reports and images of CXR. Ultrasonographic findings regarding pneumothorax (PNX), subcutaneous emphysema (SCE), lung consolidations (LC), pleural effusions (PE) and hemi-diaphragm position were collected and compared to corresponding CXR findings. Inter-rater agreement between two techniques was determined by Cohen's kappa-coefficient.

Results: Twenty-four patients were selected. Inter-rater agreement showed a moderate magnitude for PNX (Cohen's Kappa 0.5), a slight/fair magnitude for SCE (Cohen's Kappa 0.21), a fair magnitude for PE (Cohen's Kappa 0.39), no agreement for LCs (Cohen's Kappa 0.06), high levels of agreement for position of hemi-diaphragm (Cohen's Kappa 0.7).

Conclusion: Analysis of agreement between chest X-ray and chest US showed that ultrasonography is able to detect important findings for surgeons. Limitations and advantages have been found for both chest $\mathrm{X}$-ray and chest US. Knowing the limits of each one is important to really justify and optimize the use of ionizing radiations.
\end{abstract}

Keywords: Chest ultrasound, Innovative biotechnologies, Thoracic surgery, Chest X-ray, Ultrasonography

\section{Background}

After thoracic surgery, surgeons need to monitor and manage clinical course of patients. Some important pathological findings are constantly searched and focused on to take decisions about chest tube removal, vacuum suction, antibiotic therapies, bronchoscopy etc.

\footnotetext{
* Correspondence: smargiassi.a@gmail.com

This work has been accepted as poster discussion at ERS congress, Paris 2018.

${ }^{\dagger}$ Andrea Smargiassi and Riccardo Inchingolo contributed equally to this work. ${ }^{1}$ Respiratory Medicine, Fondazione Policlinico Universitario A. Gemelli IRCCS, Rome, Italy

Full list of author information is available at the end of the article
}

Findings that are always evaluated are pneumothorax, subcutaneous emphysema, pleural effusions, lung consolidations and diaphragm displacement. Chest $\mathrm{x}$-ray (CXR) during the first $48 \mathrm{~h}$ after surgery is the easiest diagnostic technique to perform in order to check these alterations although its use is controversial [1-3].

However, in the last years chest ultrasonography (Chest US) has been proposed as a bedside technique useful in many pathologic conditions. It has already been demonstrated its utility just for those conditions previously listed [4-7].

(C) The Author(s). 2019 Open Access This article is distributed under the terms of the Creative Commons Attribution 4.0 International License (http://creativecommons.org/licenses/by/4.0/), which permits unrestricted use, distribution, and reproduction in any medium, provided you give appropriate credit to the original author(s) and the source, provide a link to the Creative Commons license, and indicate if changes were made. The Creative Commons Public Domain Dedication waiver (http://creativecommons.org/publicdomain/zero/1.0/) applies to the data made available in this article, unless otherwise stated. 
Aim of this paper is to study the level of agreement for those pathological conditions between chest ultrasonography and chest X-ray and to focus on cases of disagreement to identify advantages and limits of each technique. The final goal of this study is to understand whether chest US can limit, optimize and justify (not replace) ionizing radiations during the first $48 \mathrm{~h}$ after thoracic surgery and whether chest US can lead to rational use of chest X-ray.

\section{Materials and methods \\ Study population}

Study population ruled in patients admitted to Thoracic Surgical Department of University Hospital "Agostino Gemelli", Rome, Italy, who have undergone to thoracic surgery either in open chest technique (lateral thoracotomy/mini-thoracotomy) or in uni/multi-portal VATS. Patients undergoing pneumonectomy have been ruled out because of ICU-admission after surgery. Patients were retrospectively selected in a 2-month sample period, from January to February 2017. In our structure, patients undergo routinely chest ultrasonography after thoracic surgery in the first $48 \mathrm{~h}$. Selected patients have routinely undergone to both Chest ultrasonography and Chest X-Ray in the first $48 \mathrm{~h}$ after thoracic surgery. Patients have been included in this retrospective analysis when chest X-ray and chest ultrasonography have been performed one from the other in less than $3 \mathrm{~h}$. No clinical changes had to be reported before performing the second technique.

\section{Chest ultrasonography}

Ultrasonographic assessment was performed using MyLab $^{\text {ma }} 50 \mathrm{CV}$ machine (Esaote, Genova, Italy) equipped with convex $(2-5 \mathrm{MHz})$ and linear $(7-13 \mathrm{MHz})$ probes.

All ultrasonographic evaluations were performed by pneumologists (AS and RI) and by a thoracic surgeon (MC) with a consolidated expertise in lung ultrasonography, blinded to Chest X-rays reports and images.

Each patient was asked initially to stay seated for dorsal sonographic scans, then to lie in a supine position for anterior and lateral scans. Monolateral ultrasonographic evaluation was performed according to surgical procedure. A bilateral assessment was performed only to

Table 1 Chest US findings

\begin{tabular}{ll}
\hline Chest US findings & \\
\hline Pneumothorax & 20 \\
Subcutaneous Emphysema & 16 \\
Pleural effusion & 18 \\
Lung consolidation & 15 \\
Elevated Hemidiaphragm & 5 \\
\hline
\end{tabular}

Table 2 Chest $X$-ray findings

\begin{tabular}{ll}
\hline Chest X-ray findings & \\
\hline Pneumothorax & 15 \\
Subcutaneous Emphysema & 10 \\
Pleural effusion & 13 \\
Lung consolidation & 15 \\
Elevated Hemidiaphragm & 3 \\
\hline
\end{tabular}

compare sliding sign e position of hemi-diaphragm between right and left hemithorax.

The convex probe was used firstly to look for pleural effusions, lung consolidations, curtain sign and position of emidiaphagm. Then, the linear probe was used to detect sliding sign, pneumothorax (PNX), subcutaneous emphysema and pleural abnormalities. Images and videos were acquired and stored. A subsequent evaluation by 2 pneumologist and a thoracic surgeon (AS, RI, $\mathrm{MC}$ ) with high expertise in lung ultrasonography was performed in order to collect and report in particular 5 ultrasonographic findings:

1) Pneumothorax (PNX): it is described by the detection of lung points, the focal absence of sliding of the pleural line and the absence of sonographic interstitial syndrome [5].

2) Subcutaneous Emphysema (SCE): it is characterized by the presence of air under the skin in the layers of the chest wall. Air is able to hamper the ultrasound beam to go beyond tissues till to the pleural line. It is easily detected by ultrasounds but it can hide ultrasonographic findings beyond the air barrier. It has a characteristic crackling feel to the touch [6].

3) Pleural Effusion (PE): it is described as hypoanechoic fluid collection, bordered by the parietal pleural layer on the surface and by the visceral layer in its depth. Free-flowing pleural effusions lay in lower areas for gravitational effects. Instead, loculated pleural effusions appear as well-defined fluid structure $[5,8,9]$.

4) Lung consolidations (LC): In chest ultrasonography, they appear as subpleural hypoechoic solid structures that are multiform in shape and dimensions. Usually well delimitated, LC can be surrounded by focal sonographic interstitial

Table 3 Agreement for Pneumothorax (PNX)

\begin{tabular}{lll}
\hline PNX & Chest X-ray & \\
\cline { 2 - 3 } Chest US & Negative & Positive \\
\hline Negative & 4 & 0 \\
Positive & 5 & 15 \\
\hline
\end{tabular}

Cohen's Kappa: 0.5

Percentage of agreement: $79 \%$

\section{5}

0

(3)

5 .

\section{.}


Table 4 Agreement for Subcutaneous Emphysema (SCE)

\begin{tabular}{lll}
\hline SCE & Chest X-ray & \\
\cline { 2 - 3 } Chest US & Negative & Positive \\
\hline Negative & 6 & 2 \\
Positive & 8 & 8 \\
\hline
\end{tabular}

Cohen's Kappa: 0.21

Percentage of agreement: $58 \%$

syndrome. This pattern is described as alterations of the pleural line with merged vertical artifacts and B-lines, which is typically indicative of a pre-consolidated state of the lung [7].

5) Position of hemi-diaphragm: using a convex probe it is possible to detect the curtain sign described as the border between the artifactual field of expanded lung and the morphological field of parenchymal organs in abdomen. Curtain sign is indicative of the position of hemi-diaphragm when compared with the position of the contralateral. Whether a freeflowing PE or a LC are detected, curtain sign is not identifiable. In this case hemidiaphragm is identified by using both convex and linear probe. It appears as a thin three-layer muscle lying between parenchymal organs in abdomen and either LC or PE or both $[5,10,11]$.

After having revised Chest US, operators declared if it would have been useful to perform Chest X-ray for a panoramic view or if chest US findings could be sufficient to get the most relevant information for the surgeon after surgery.

\section{Chest X-ray}

All patients systematically undergo AP-projection chest $\mathrm{X}$-ray in inspiration during the first $48 \mathrm{~h}$ after surgery. Chest X-ray was required to get relevant information for surgeons in order to take medical subsequent decisions (e.g. removal of chest tube drainage, connection to vacuum, bronchoscopy).

Reports and images have been obtained in order to collect the same findings listed for chest ultrasonography: pneumothorax, subcutaneous emphysema, pleural effusion, lung consolidation, and position of hemi-diaphragm compared with contralateral.

Table 5 Agreement for Pleural effusion (PE)

\begin{tabular}{lll}
\hline PE & Chest X-ray & \\
\cline { 2 - 3 } Chest US & Negative & Positive \\
\hline Negative & 5 & 1 \\
Positive & 6 & 12 \\
\hline
\end{tabular}

Cohen's Kappa: 0.39

Percentage of agreement: $70 \%$
Table 6 Agreement for Lung consolidation (LC)

\begin{tabular}{lll}
\hline LC & Chest X-ray & \\
\cline { 2 - 3 } Chest US & Negative & Positive \\
\hline Negative & 3 & 6 \\
Positive & 6 & 9
\end{tabular}

Cohen's Kappa: 0.06

Percentage of agreement: $50 \%$

\section{Statistical analysis}

A descriptive analysis was reported by computing mean values and standard deviations. Inter-rater agreement between chest US and chest X-ray for the 5 listed findings was determined by Cohen's kappa-coefficient statistic. Inter-rater agreement magnitude has been considered based on Landis and Koch proposal: Cohen's kappa values $<0$ as indicating no agreement; $0-0.20$ as slight, $0.21-0.40$ as fair, $0.41-0.60$ as moderate, $0.61-$ 0.80 as substantial, and $0.81-1$ as almost perfect agreement. Simple percentage agreement was also reported.

No comparison with gold standard test (chest CT scan) was available because it was not clinically and ethically required for this study population.

\section{Results}

The study population consisted of 24 patients ( 15 males) with an average age of $63.6 \pm 15.5$ years. Fourteen patients have undergone to uni-portal VATS, 2 patients to multi-portal VATS, 5 patients to thoracotomy, 1 case of mini-thoracotomy and 2 cases of robotic thymectomy.

Chest ultrasonography was performed 32,8 $\pm 8,8 \mathrm{~h}$ after surgery. Chest US was able to detect 20 PNX (in all cases lung point was identified), 16 cases of subcutaneous emphysema, 18 pleural effusions, 15 lung consolidations and 5 cases of elevated hemidiaphragm compared with contralateral (Table 1).

Chest X-ray revealed 15 PNX, 10 SCE, 13 PE, 15 LC, 3 elevated hemidiaphragm (Table 2).

Both chest Us and chest X-ray could detect contemporaneously more than one finding in the same patients.

Agreement study between the two techniques was performed for each finding.

As far as PNX is concerned, percentage of agreement was $79 \%$ with Cohen's Kappa 0.5, resulting in a moderate magnitude of inter-rater agreement. Both chest US and chest X-ray detected PNX in 15 cases. Both techniques

Table 7 Agreement for Diaphragm Displacement (DD)

\begin{tabular}{lll}
\hline DD & Chest X-ray & \\
\cline { 2 - 3 } Chest US & Negative & Positive \\
\hline Negative & 18 & 0 \\
Positive & 2 & 3
\end{tabular}

Cohen's Kappa: 0.70

Percentage of agreement: $91 \%$ 


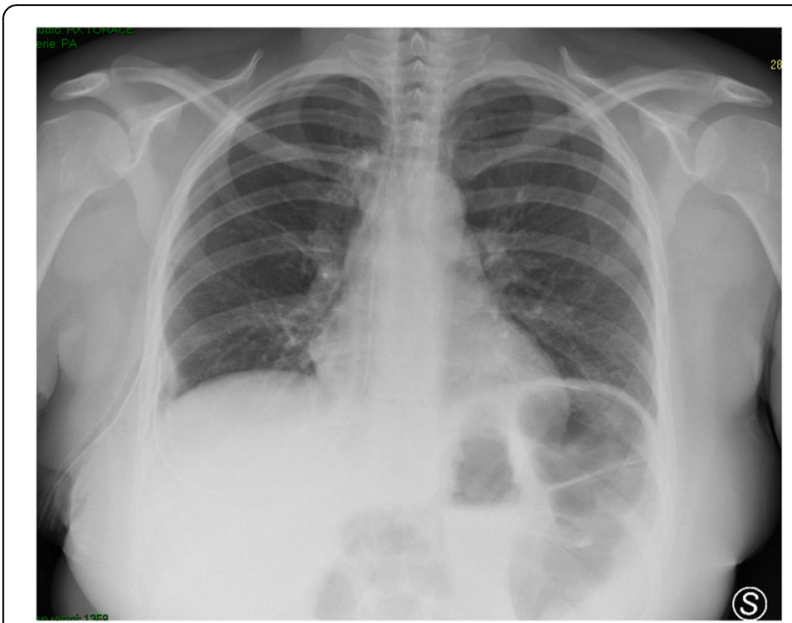

Fig. 1 A case of subcoutaneous emphysema localized only around the surgical wound. It has been missed by chest US because of local medications

didn't detect it in 4 cases. Discordance in 5 cases (Table 3).

SCE has shown $58 \%$ of agreement with Cohen's Kappa 0.21 , indicating a slight/fair magnitude. In this case, both techniques were in agreement both to identify SCE in 8 subjects and to not identify it in 6 subjects. Discordance in 10 cases (Table 4).

As to PE, agreement was 70\% and Cohen's Kappa 0.39, showing a fair magnitude. In 12 cases, PE was positively detected by both techniques. In 5 cases PE was concordantly absent. Discordance has been reported for 7 cases (Table 5).

For LC, instead, no agreement has been found (Cohen's Kappa 0.06) with percentage of concordance of $50 \%$. Disagreement was reported therefore in 12 out of 24 patients (Table 6).

Finally, diaphragmatic displacement has shown high levels of concordance (91\%) with substantial inter-rater agreement (Cohen's Kappa 0.7). Normal position in 18 cases and agreement on elevation in 3 subjects. Only 2 cases of disagreement were reported (Table 7).

\section{Discussion}

Level of agreement between chest X-ray and chest US has been computed for 5 pathological findings that are important for surgeons managing clinical course after surgery. Cases of discordance are discussed below for each finding in order to identify advantages and limits of each technique.

As to PNX, chest US and Chest X-ray showed a moderate inter-rater agreement. Discussion deserves for case of discordance. In 5 cases Chest Us was positive for PNX and chest X-ray negative. No cases were positive for Chest X-ray and negative for Chest US. In all 5 cases Chest US identified PNX by detecting lung point(s).

Lung point has been reported in literature with high specificity for PNX $[12,13]$. When detected, PNX is always present. Thus, we can conclude that chest US has higher sensitivity for PNX, as already reported in literature, if compared with chest X-ray. It has been reported that Chest X-ray has good specificity for PNX, but it has no high levels of sensitivity [14], especially when performed in one AP-projection and in supine position $[15,16]$. However, although chest US can be considered more specific and more sensible than X-ray, a limitation has to be discussed: US is not useful to correctly estimate the extension of PNX. We can suspect big amount of PNX when lung point is detected, in clinostatic position, far from the parasternal line of the thorax and near to axillary lines. In these cases, performing chest X-ray is mandatory in order to correctly estimate extension [17].

Instead, when chest X-ray is not able to detect PNX, we can believe that it has minimal extension without clinical significance after surgery. The importance to detect even minimal amount of PNX could be useful; however in some circumstances like persistent air leaks after surgery or in case of necessity for mechanical

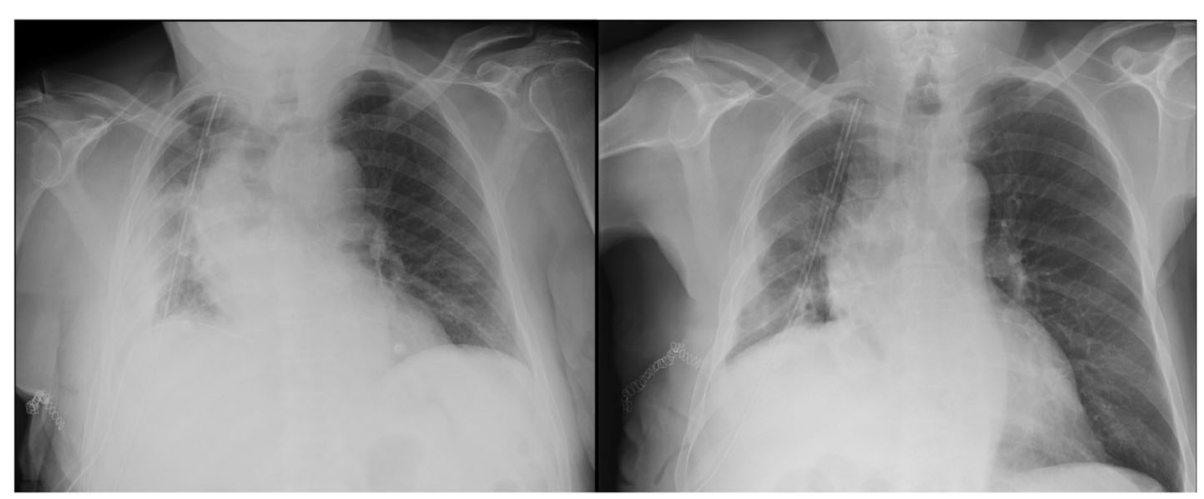

Fig. 2 Chest x-ray performed before (on the right) and after (on the left) bronchoscopy. Chest x-ray reported the presence of loculated pleural effusion, which was correctly identified as obstructive atelectasis by Chest US (see Fig. 4) 


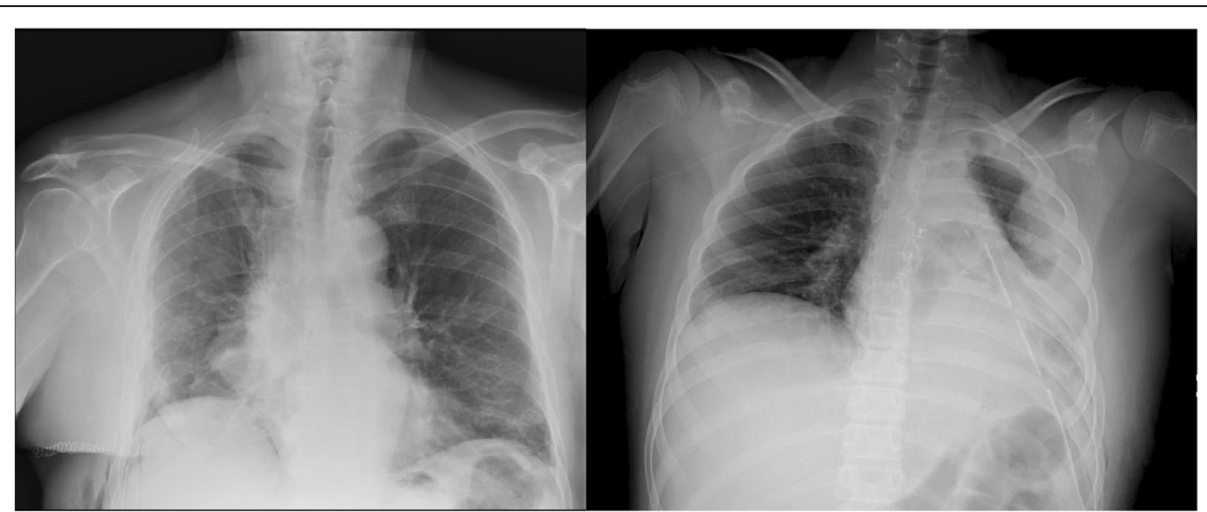

Fig. 3 On the right: a case of elevated hemidiaphragm detected by both chest US and chest X-ray. On the left: Elevated left hemidiagram not easily detectble by chest $x$-ray because of concomitant pleural effusion and basal lung consolidation

ventilation or CPAP. To summarize, we believe that chest US might be useful both to detect even minimal amount of PNX with high sensitivity and specificity, and to correctly optimize the use of ionizing radiations when required.

Subcutaneous emphysema showed a slight/fair inter-rater agreement between the two techniques. Ten cases of discordance need to be discussed. In 8 cases out of these 10, chest US was positive for SCE and chest X-ray was negative. Chest US is very sensitive for air leaks in the tissue layers of the chest wall. Air is able to hamper the ultrasounds to go beyond tissues. Thus, SCE is easily detected, also minimal amounts, when ultrasounds are not able to reach the pleural line and are reflected while crossing tissues [5].

Hence, it is not surprising whether chest US has been able to detect more SCE than chest X-ray. However, small amounts of SCE are not clinically relevant.

In 2 cases out of 10, instead, chest X-ray reported SCE and chest US was negative. In these two cases, SCE, not clinically relevant, was focally localized around the surgical wound. Chest US wasn't able to detect SCE because of local medication with gauze and patch that had hampered local examination (Fig. 1).

Also for SCE we believe that chest US could be useful to better understand extension and clinical importance. The limit of US examination in these cases is that extensive SCE diffusely hampers the ultrasound beam to asses pleural and lung findings. Chest US examination is limited when SCE is diffuse and chest X-ray is mandatory.

For PE, it is known that Chest US can represent the gold-standard technique [18-20]. Inter-rater agreement with Chest X-ray showed a fair magnitude. Seven cases of discordance have been reported. It is not surprising that Chest US was able to identify 6 cases that chest X-ray missed. Pleural effusions, also minimal amounts, are well detected by ultrasounds. Only in one case chest X-ray reported loculated PE in disagreement with US. In this case, chest US was confident for lung consolidation, for instance obstructive atelectasis. The patient underwent multiple bronchoscopies to remove obstruction by secretions. Figure 2 reported chest X-ray performed pre- and post-bronchoscopies. In our sample chest US

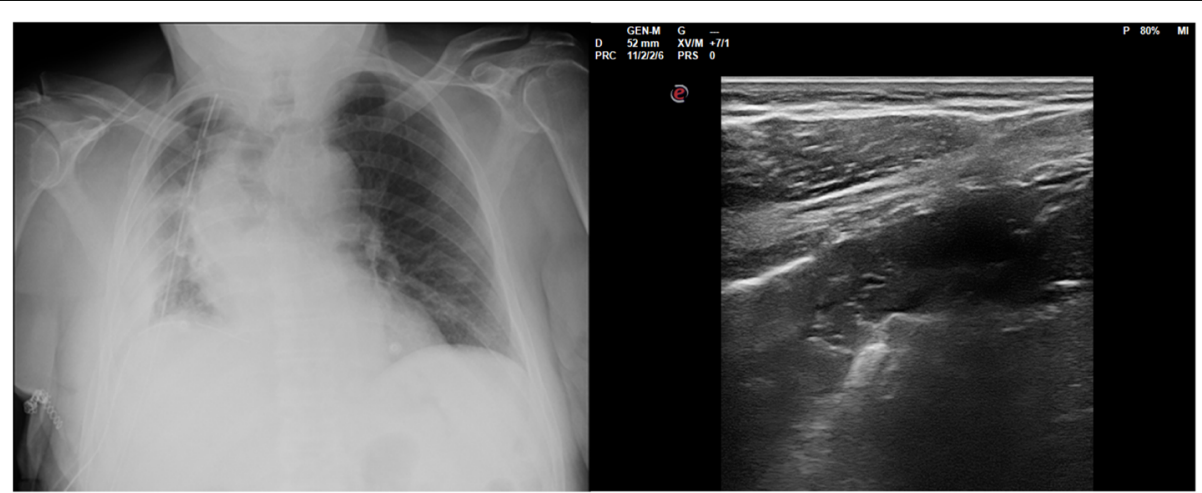

Fig. 4 The same case of Fig. 2. Chest US reported LC compatible with obstructive atelectasis and reduction of volume of the hemithorax. Chest $X$-ray was required for a panoramic view 
confirmed to be referral technique for PE as already reported in literature.

As far as LCs are concerned, chest X ray and chest US showed the worst level of agreement. In 6 cases chest $\mathrm{X}$-ray reported consolidations that chest US wasn't able to find. All 6 cases have been described as central consolidations compatible with lung contusions and atelectasis as result of surgery.

Central consolidations are not assessable by ultrasounds because the ultrasound beam is not able to explore inflated lung parenchyma [4, 7]. The condition to become detectable by ultrasounds is that the consolidation has to reach and touch visceral pleura. In these cases, ultrasounds are able to detect even small consolidations, difficult to be seen by chest X-ray [21, 22]. This is the reason why in other 6 cases chest US reported consolidations that weren't missed by one AP-projection Chest X-ray.

However, it is important to say that lung contusions after surgery are frequent and not clinically relevant. It is important, instead, to detect flogistic LCs and pneumonias in that period. It has already been reported in literature that chest US has good sensitivities for pneumonias, better than chest X-ray [21, 22].

The limit for chest US after surgery for detecting pneumonias could be represented by the presence of large pneumothorax or massive SCE that hampers ultrasonographic assessment. As already discussed before, however, in case of either suspected large pneumothorax or massive SCE, chest X-ray is mandatory.

Finally, position of hemi-diaphragm showed significant inter-rater agreement between the two techniques. Only 2 cases of discordance have been reported. One case of elevated hemidiaphragm on the left and one case on the right. In both cases chest US revealed an elevated hemi-diaphragm which was missed by one AP-projection Chest X-ray. Chest X-ray wasn't able to clearly detect the position of hemi-diaphragm because of the presence of pleural effusion and basal lung consolidation that covered diaphragm displacement. (Fig. 3).

After echographic assessment, in 5 cases out of 24, it would have been useful to perform chest $x$-ray. Three cases of massive SCE, one case of obstructive atelectasis with reduction of volume of the hemithorax for a panoramic view (Fig. 4) and one case of hydro-pneumothorax.

\section{Conclusion}

During the first $48 \mathrm{~h}$ after thoracic surgery, surgeons usually need chest X-ray to check some important findings that have to be related to clinical conditions. Analysis of agreement between chest X-ray and chest US showed that ultrasonography, easily performed bedside, is able to detect important findings for surgeons. Some limitations have been found and discussed for both chest
X-ray and chest US. However, knowing the limits of chest US is important to really justify and optimize the use of chest X-ray in some cases. There is no competition between these two techniques, but it must be the physician that has to choose the better one, knowing advantages and limitations of each one, case by case. In this optimized diagnostic path, chest US can limit the daily use and justify rational use of CXR. [23, 24]. This retrospective pilot analysis could represent the first step towards the development of a prospective study on the usefulness of chest ultrasound after thoracic surgery.

\section{Abbreviations}

chest US: Chest Ultrasonography; CXR: Chest X-ray; LC: Lung Consolidations; PE: Pleural Effusions; PNX: Pneumothorax; SCE: Subcutaneous Emphysema

\section{Acknowledgements}

Not applicable.

\section{Funding}

No conflicts funding have to be declared by the authors in relation to this work.

\section{Availability of data and materials}

The datasets used and/or analysed during the current study are available from the corresponding author on reasonable request.

\section{Authors' contributions}

AS and RI performed chest ultrasonography, analyzed and interpreted the patient data and were major contributors in writing the manuscript. MC and LPC performed chest ultrasonography, analyzed and interpreted the patient data. SL collected data and write the manuscript. GMC made substantial contributions to conception and design, analyzed and interpreted the patient data and performed the statistical analysis. SM and LR made substantial contributions to conception and design, analysis and interpretation of data. All authors read and approved the final manuscript.

\section{Ethics approval and consent to participate}

IRB (Institutional Review Board) approval of "Fondazione Policlinico Universitario A. Gemelli IRCCS" was obtained for this retrospective analysis IRB: P/ CE 5857/19.

\section{Consent for publication}

Not applicable.

\section{Competing interests}

No competing interests have to be reported by the authors in relation to this work. AS and LR are Associate Editors of Multidisciplinary Respiratory Medicine.

\section{Publisher's Note}

Springer Nature remains neutral with regard to jurisdictional claims in published maps and institutional affiliations.

\section{Author details}

${ }^{1}$ Respiratory Medicine, Fondazione Policlinico Universitario A. Gemelli IRCCS, Rome, Italy. ${ }^{2}$ Thoracic Surgery, Fondazione Policlinico Universitario A. Gemelli IRCCS, Rome, Italy. ${ }^{3}$ Università Cattolica del Sacro Cuore, Rome, Italy. 
Received: 25 July 2018 Accepted: 20 January 2019

Published online: 04 March 2019

\section{References}

1. Whitehouse MR, Patel A, Morgan JA. The necessity of routine post thoracostomy tube chest radiographs in post-operative thoracic surgery patients. Surgeon. 2009;2:79-81.

2. French DG, Dilena M, LaPlante S, Shamji F, Sundaresan S, Villeneuve J, et al. Optimizing postoperative care protocols in thoracic surgery: best evidence and newtechnology. J Thorac Dis. 2016;8(Suppl 1):S3-S11.

3. Reeb J, Falcoz PE, Olland A, Massard G. Are daily routine chest radiographs necessary after pulmonary surgery in adult patients? Interact Cardiovasc Thorac Surg. 2013;17:995-8.

4. Volpicelli G, Elbarbary M, Blaivas M, Lichtenstein DA, Mathis G, Kirkpatrick AW, et al. International liaison committee on lung ultrasound (ILC-LUS) for international consensus conference on lung ultrasound (ICC-LUS): international evidence-based recommendations for point-of-care lung ultrasound. Intensive Care Med. 2012:38:577-91.

5. Zanforlin A, Giannuzzi R, Nardini S, Testa A, Soldati G, Copetti R, et al. The role of chest ultrasonography in the management of respiratory diseases: document I. Multidiscip Respir Med. 2013;9(8(1)):54

6. Chira R, Chira A, Mânzat Săplăcan R, Nagy G, Bințințan A, Mircea PA. Pleural ultrasonography. Pictorial essay Med Ultrason. 2014;16(4):364-71.

7. Smargiassi A, Inchingolo R, Soldati G, Copetti R, Marchetti G, Zanforlin A, et al. The role of chest ultrasonography in the management of respiratory diseases: document II. Multidiscip Respir Med. 2013;9(8(1)):55.

8. Koegelenberg CF, von Groote-Bidlingmaier F, Bolliger CT. Transthoracic ultrasonography for the respiratory physician. Respiration. 2012:84(4):337-50

9. Smargiassi A, Inchingolo R, Zanforlin A, Valente S, Soldati G, Corbo GM. Description of free-flowing pleural effusions in medical reports after echographic assessment. Respiration. 2013;85(5):439-41.

10. Smargiassi A, Inchingolo R, Tagliaboschi L, Di Marco BA, Valente S, Corbo GM. Ultrasonographic assessment of the diaphragm in chronic obstructive pulmonary disease patients: relationships with pulmonary function and the influence of body composition - a pilot study. Respiration. 2014;87(5):364-71.

11. Sferrazza Papa GF, Pellegrino GM, Di Marco F, Imeri G, Brochard L, Goligher

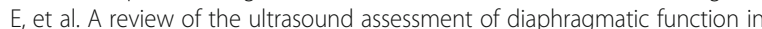
clinical practice. Respiration. 2016;91(5):403-11.

12. Lichtenstein $D$, Mezière $G$, Biderman $P$, Gepner $A$. The "lung point": an ultrasound sign specific to pneumothorax. Intensive Care Med. 2000;26(10):1434-40.

13. Reissig A, Copetti R, Kroegel C. Current role of emergency ultrasound of the chest. Crit Care Med. 2011;39(4):839-45.

14. Alrajab S, Youssef AM, Akkus NI, Caldito G. Pleural ultrasonography versus chest radiography for the diagnosis of pneumothorax: review of the literature and meta-analysis. Crit Care. 2013;23(17(5)):R208.

15. Volpicelli G. Sonographic diagnosis of pneumothorax. Intensive Care Med. 2011:37(2):224-32.

16. Soldati G, Testa A, Sher S, Pignataro G, La Sala M, Silveri NG. Occult traumatic pneumothorax: diagnostic accuracy of lung ultrasonography in the emergency department. Chest. 2008;133(1):204-11.

17. Williamson JP, Grainge C, Parameswaran A, Twaddell SH. Thoracic ultrasound: what non-radiologists need to know. Curr Pulmonol Rep. 2017;6(1):39-47.

18. Hooper C, Lee YC, Maskell N. BTS pleural guideline group. Investigation of a unilateral pleural effusion in adults: British thoracic society pleural disease guideline 2010. Thorax. 2010;65(Suppl2):4-17.

19. McLoud TC, Flower CD. Imaging the pleura, sonography, $C T$, and MR imaging. Am J Roentgenol. 1991;156(6):1145-53.

20. Smargiassi A, Pasciuto G, Pedicelli I, Lo Greco E, Calvello M, Inchingolo R, et al. Chest ultrasonography in health surveillance of asbestos-related lung diseases. Toxicol Ind Health. 2017:33(6):537-46.

21. Reissig A, Copetti R, Mathis G, Mempel C, Schuler A, Zechner P, et al. Lung ultrasound in the diagnosis and follow-up of community-acquired pneumonia: a prospective, multicenter, diagnostic accuracy study. Chest. 2012;142(4):965-72.
22. Reissig A, Copetti R. Lung ultrasound in community-acquired pneumonia and in interstitial lung diseases. Respiration. 2014;87(3):179-89.

23. John MM, Bibi S. Daily routine chest radiographs after pulmonary surgery. eComment Interact Cardiovasc Thorac Surg. 2013;17(6):998-9.

24. Nagy P, Antony C, Hegedüs B, Kampe S, Ploenes T, Aigner C, et al. Sameday routine chest- $X$ ray after thoracic surgery is not necessary! Zentralbl Chir. 2018;143(1):96-101.

\section{Ready to submit your research? Choose BMC and benefit from:}

- fast, convenient online submission

- thorough peer review by experienced researchers in your field

- rapid publication on acceptance

- support for research data, including large and complex data types

- gold Open Access which fosters wider collaboration and increased citations

- maximum visibility for your research: over $100 \mathrm{M}$ website views per year

At $\mathrm{BMC}$, research is always in progress.

Learn more biomedcentral.com/submissions 